\title{
Editorial
}

\section{Academic Publishing in China}

\author{
Michael A. Peters \\ Distinguished Professor, Faculty of Education, \\ Beijing Normal University, PR China \\ mpeters@bnu.edu.cn
}

We are pleased to see the publication of the first issue of The Beijing International Review of Education. The journal was the original idea of Xudong Zhu, Dean of Education of the Faculty of Education at Bejing Normal University (BNU) and one of the Editors-in-Chief. Several years ago we met at the American Educational Research Association (AERA) at the BNU reception and he indicated that he wanted to set up a new education journal in English at BNU. He also asked me whether I was interested in helping him to establish the journal. The idea of setting up a new journal was appealing to me. Over the course of my career I had established many different journals. I have also edited Educational Philosophy and Theory for over twenty years, now an SSCI journal with some fourteen issues per year including a China Open Access issue. Tina Besley (my wife) and I, then both professors at the University of Waikato, met with Xudong Zhu again at AERA at the San Antonio meeting in 2017. We had done our research and subsequently decided that BNU, as China's top university in education, would be an interesting place to work, a great opportunity to work with Chinese colleagues, and a place to learn about Chinese culture. The idea excited us the more we thought about it. We were particularly interested in setting up a genuine East-west dialogue in educational theory and philosophy.

Various editorial positions have given us the privilege of being in touch with most fields and the opportunity to read contributions from scholars from around the world. On meeting Professor Xudong Zhu and receiving his invitation we became convinced that BNU would be an interesting move for us to develop the significance of philosophy of education especially in the an 
engagement with Chinese colleagues. Having completed our first semester we can now say that the move has been both successful and enlightening for us: the faculty, student and administrators have been helpful and charming and our cultural reception has only increased our willingness to work with the Faculty of Education at BNU to be competitive in an academic world historically created in part by a knowledge capitalism dominated by big western publishers. This is a theme that we will be addressing in future issues - the political economy of knowledge capitalism and the distortions it introduces into the global system of higher education, as well as the concept of knowledge socialism.

BNU itself is a flagship normal university in China, as the University's webpage indicates:

Beijing Normal University, a key university under the administration of the Ministry of Education, is a renowned institution of higher education known for teacher education, education science and basic learning in both the arts and the sciences. The university's predecessor, the Normal College of the Imperial University of Peking, was founded in 1902. In 1908, the school name was changed to Advanced Normal College of the Imperial University and the school became independent. In 1912, the name changed again, to Beijing Advanced Normal School, and then, in 1923, the name changed yet again to Beijing Normal University, the first Normal University in Chinese history. In 1931 and 1952, respectively, Peking Women's Normal University and Fu Jen Catholic University merged to create Beijing Normal University.

For over a century, Beijing Normal University has from the beginning shared a fate as regards the Chinese people's struggle to gain independence, freedom, democracy and prosperity, and the university has played a significant role in patriotic movements that have included the May 4th Movement (1919) and the December 9th Movement (1935). https:// english.bnu.edu.cn/about_bnu/general_information/index.htm

The full history is available on the website. It lists the important scholars and renowned intellectuals and provides the background for the establishment of the national key universities built during the time of China's Seventh and Eighth Five-Year Plans, the "211 Project" Construction Program during the time of the Ninth Five-Year Plan, and the "985 Project" Construction program. At this point in the evolution of a global system of higher education we still hear very little about Chinese scholars, their research and philosophical outlook in the West.

I feel privileged to help Xudong lead an editorial team to establish an English language journal for Education at BNU and want to take the opportunity to mention and thanks the members of the editorial team including Distinguished 
Professor Tina Besley, Dr. Huajun Zhang, Dr. Kwok Kuen Tsang, Dr. Heyi Zhang, Dr. Ke Lin (all from BNU) and Professor Jun Li (Western University in Canada). Dr Hong Wan has recently joined us as Editorial Manager. The full list of board members, members of the international board, and reviewers are available on the journal website. We wish to thank them for their encouragement and involvement. We also wish to thank also Director Yang Yang of the International Office in the Faculty and her team as well as Ms Huang Xin, in charge of Human Resources. Both teams have worked hard to help us get established and to organise the journal.

Certainly, a new English journal in Education is one way that the Faculty of Education at BNU can increase its impact and visibility in Education and to attract international scholars. The journal also provides a vehicle for developing a wider publishing culture that is not driven by "publish or perish" but rather one that aims to encourage scholars to understand the history, economics of publishing as well as its production and editorial side. On the basis of this understanding academics can begin to understand the mega-trends publishing and its technological disruption, in order to experiment and innovate.

Modern academic publishing in China lags behind the West although this is rapidly changing. The global knowledge system represented by some 20 thousand journals is less than $45^{\circ}$ years old. Journal des Sçavans, the first journal was published in Paris in 1665 and The Philosophical Transactions of the Royal Society was established 1665 with Henry Oldenburg as first Editor (and Secretary) to become an official publication in $175^{2}$. National science academies were developed in the 18th Century, less than 250 years ago - for example, the American Academy of Arts \& Sciences was established in 1780. The full story would require recognition of the development of science and especially information science during the two world wars. Global science communication emerged in the 2oth century with advent of the first electronic journals in the early 1990s and the development of open access as well as a number of mergers and acquisitions of big publishers. These changes included the growth of companies like Clarivate Analytics that provide scientific citation analysis indexes and look to improve the innovation cycle for nations and institutions. ${ }^{1}$ We are only at an early stage of the development and evolution of the global system of journal publishing passing through the ages dominated in turn by traveling scholars and the exchange of scientific letters, technologies based on the printing press, electronic technologies that emerged in the early 1990s creating scholarly networks of communication, and the age of the video journal that is developing only in the last decade.

1 Clarivate reportedly has 150 years of zoological genus records, 1.75 million journal publications and more than 200,00o clinical trial records, https://clarivate.com/about-us/what-we-do/. 
Understanding and engaging with the political economy of publishing is now critical to success in higher education and an increasingly technologyand-science driven economy. As Sarah Boon (2017) explains: "According to research from the University of Ottawa, in 2009 we passed the 50 million mark in terms of the total number of science papers published since 1665, and approximately 2.5 million new scientific papers are published each year." ${ }^{2}$ Boon (2017) indicates that "As of 2014 there were approximately 28,100 active scholarly peer-reviewed journals" quoting Mark Ware's (2015) The STM Report An overview of scientific and scholarly journal publishing ${ }^{3}$ and this is not counting the massive growth in predatory journals. The academic publishing market is $\$ 25$ billion a year, mostly located in the US and Europe, with a very small but growing market in Asia. A huge proportion of scientific papers are never cited. Dahlia Remler (2018) blogs:

Non-citation rates vary enormously by field. "Only" $12 \%$ of medicine articles are not cited, compared to about $82 \%$ (!) for the humanities. It's $27 \%$ for natural sciences and $32 \%$ for social sciences ... One third of social science articles go uncited! ... remember that much of their most prestigious research is published in books. On the other hand, at least in literature, many books are rarely cited too. ${ }^{4}$

We have to remember that the birth of the peer review system was a late invention. Peer review was introduced to scholarly publication in 1731 by the Royal Society of Edinburgh, which published a collection of peer-reviewed medical articles. "Science and The Journal of the American Medical Association did not use outside reviewers until after 1940," (Spier, 2002). The Lancet did not implement peer-review until 1976 (Benos et al., 2006). Yet today, peer review is the "golden standard" in evaluation of everything from scholarly publication to grants to tenure decisions (Shema, 2014).

China is now catching up with the West in academic publishing. Of the number of Chinese English-language journals (CELAJS) only six were published up until 1980 s ( 2 have ceased publication). In 1980 there were 83 in China; in 1990 there were 105; 2000 saw the establishment of 15 new journals. Rapid growth in CELJS occurred between 2006 and 2011 but mostly in the science, technology and medicine disciplines. There are now some 435 CELJs, of which $62.3 \%$ are published in association with a western publisher. By 2010, a total of 108

2 http://blog.cdnsciencepub.com/21st-century-science-overload/.

3 https://www.stm-assoc.org/2015_02_20_STM_Report_2015.pdf.

4 http://blogs.lse.ac.uk/impactofsocialsciences/2014/04/23/academic-papers-citation -rates-remler/. 
university presses (UPs) existed in China publishing about 883 academic journals (25\%). Large scholarly publishers such as China Science Publishing Group Co., Ltd (CSPG) and Social Sciences Academic Press (SSAP) of Chinese Association of Social Science (CASS), account for the massive growth of $18 \%$ pa 1999-2008 in scientific papers (Zhang et al., 2002). Lu Jinxiu (2004: 120) reports: "Today in China, there are more than 8000 academic journals, of which more than 4600 can be considered scientific. About 1400 cover health science (medicine and public health)." Lu states that "some 189 scientific journals are published in English, of which 29 are health-science journals" (ibid).

Information sources on English language journals or, indeed, academic publishing in China are few with very little information available on developments after 2008. For instance, The Institute of Scientific and Technical Information of China, ${ }^{5}$ for instance, does not publish data after 2008. Even the Wikipedia article that begins: "Today in China, there are more than 8,000 academic journals, of which more than 4,60o can be considered scientific. About 1,400 cover health science (medicine and public health)"6 seems hopelessly out of date.

Yet according to 2018 Science \& Engineering Indicators, a report published by the U.S. National Science Foundation (NSF), China has left the U.S. behind to become the largest producer of scientific articles. ${ }^{7}$ In 2016, China published more than 426 , 000 studies, which amounted to $18.6 \%$ of the publications indexed in Scopus (Elsevier's database). The U.S., with 409,000 studies, is now positioned after China. Clarivate Analytics, announced that China ranks third in the world in publishing academic papers that are a result of international collaboration. But China lags behind the U.S. in terms of citations. Sneha Kulkarni (2017) summarises the report China's International Scientific Research Collaboration Landscape (2012) produced by the National Center for Science and Technology Evaluation ${ }^{8}$ and Clarivate:

As per the 2010 data, the total number of submissions from the US ( 0.23 million) was almost double the number from China (o.11 million), and the acceptance rates of papers from the US (50.1\%) was also almost double those for China (26.8\%). Thus, in 2010, the total number of published papers from the US was almost 4 times the corresponding number for China. ${ }^{9}$

\footnotetext{
5 https://web.archive.org/web/20081216022551/http://www.istic.ac.cn/.

6 https://en.wikipedia.org/wiki/Academic_publishing_in_China.

7 https://nsf.gov/statistics/2018/nsb20181/report/sections/academic-research-and -development/highlights.

8 http://en.ncste.org/.

9 https://www.editage.com/insights/where-does-china-stand-in-global-academic-publishing.
} 
The situation is even more uneven in terms of education journals with the International Journal of Chinese Education (Brill, est. 2012), Chinese Education and Society (Taylor \& Francis, 1968), Frontiers of Education in China (Springer, 2006), Journal of East China Normal University (Educational Sciences) (East China Normal University, est. 2006), Journal of Distance Education in China (Open University of China, 1981), US-China Education Review A (David Publishing, 2008), The ECNU Review of Education (est., 2018), Journal of Computers in Education(Springer-Verlag, 2014), Smart Learning Environment (SpringerVerlag, 2014). These seven English language education journals make up a small fraction of education journals in total, ${ }^{10}$ with none of them appearing in the 131 education journals that currently make up the Education and Educational Research journal list of the Social Sciences Citation Index. ${ }^{11}$ The research quality of education journals in China has been questioned with critics suggesting "the vast majority of the articles lacked rigor, with insufficient or non-systematic literature reviews, incomplete descriptions of research design, and inadequately grounded recommendations for translating research into practice" (Zhao, et al., 2017).

It is against this background and in order to develop a culture of publishing in the Faculty of Education at Beijing Normal University that we have established The Beijing International Review of Education. We look forward to receiving new contributions and to responding to both our contributors and readers.

In this first issue of the journal we begin with an article acknowledging John Dewey's time in China "10o Years of Dewey in China, 1919-1921: A Reassessment" based on the two main primary sources of his Letters and a course of lectures he gave at Peking University that were lost and then recently recovered. My aim in part in writing this essay was to rekindle interest in Dewey and studies in China that compare his work to Confucius, rather than Chinese Marxism. I also wanted to raise some criticisms against Dewey. I invited three renowned Chinese scholars to comment on my paper - Jessica Ching-Sze Wang, Kang Zhao and, my colleague at BNU, Huajun Zhang - all of whom are noted Dewey scholars. I wish to thank them kindly for providing their insightful commentaries.

Henry A. Giroux's article "Neoliberal Fascism's war on immigrants echoes a dark and haunting past" is an indication of the public pedagogy for which he is well known. He is an exemplary public intellectual who holds the Chair for Scholarship in the Public Interest and The Paulo Freire Distinguished Scholar

10 See the ERIC index of 1,110 education journals https://eric.ed.gov/?journals; see also China Academic Journals Full-text Database, http://oversea.cnki.net/kns55/brief/result .aspx?dbPrefix=CJFD.

$11 \mathrm{http://mjl.clarivate.com/cgi-bin/jrnlst/jlresults.cgi?PC=J \& SC=HA.}$ 
in Critical Pedagogy at McMaster University in Canada. He analyses and documents the ongoing "war on immigrants" in the US including the separation of children from their parents and explains how Trump's neoliberalism has come to exhibit the characteristics of fascism including the expression of Alt Right sentiments and strong anti-democracy politics.

The next three essays are devoted to the status of the neoliberal university with Ronald Barnett, a philosopher of higher education, contemplating the concept of "The Thoughtful University" as a feasible utopia; Peter Roberts exploring performativity and the rise of big data and its implications for the professor, and Qiang Liu and his colleagues who together analyse the "Double First-Class" initiative in China. Each of these papers by seasoned commentators provide a picture of the neoliberal university. Qiang Liu, David Turner and Xiaoli Jing who work in the fields of International and Comparative Education focus their research on internationalisation of higher education. They explain the significance of the "Double First-Class" system for China. Roberts and Barnett, both philosophers of educations and world renown for their work on higher education, explore the dimensions and future of the university in the West.

In his paper "Educating with indigenous philosophy in the academy: Challenges, possibilities and responsibilities" Carl Mika, a Maori scholar from the University of Waikato, explores the status of indigenous philosophy in the university, a project that he has been in the vanguard of in New Zealand for some years.

Julie Rowlands and Trevor Gale in their paper "National research assessment frameworks, publication output targets and research practices: the compliance-habitus effect" examine relationships between national research assessment frameworks and publication output targets within academic workload models. The use Bourdieu's work as a basis for theorizing the potential impact on research practices and the academic habitus and demonstrate as the basis of their experience in United Kingdom and Australia to argue that academics in complying with publication output targets "has implications for what research is done, how, by whom and where."

Liz Jackson's "Media, Allegiance, and Civic Education" explores how students learn through their engagement with media and how it affects their civic identities. Jackson also reflects on the role that critical media education and literacy can play in general education.

Peng Liu and Qi Xiu in their paper "Teacher Professional Collaboration in China: Practices and Issues" discuss the Ministry of Education's policy promoting teacher professional collaboration that aims at building a culture aimed at improved student learning. In this light the authors examine definitions 
and particular practices of teacher collaboration as a basis for its theoretical development.

Tina Besley in her paper "Theorizing Teacher Responsibility in an Age of Neoliberal Accountability" theorizes the concept of teacher responsibility and its changes from liberal notions based on autonomy and professional accountability to neoliberal notions of "responsibilization" as a means of holding teachers accountable. She tracks the differences between the two discourses and explains how teachers have been disempowered and deprofessionalized through the neoliberal strategy of "responsibilization". In the final paper Jun Li and Jian Li examine educational policy development in China adopting a "multi-flows" perspective that focuses on three policy streams and summarizes the literature in terms of four core themes of equality, quality, efficiency and nation building.

\section{References}

Boon, S. (2017) 21st Century Science Overload, http://blog.cdnsciencepub .com/21st-century-science-overload/.

Kulkarni, S. (2017) Where does China stand in global academic publishing? https://www .editage.com/insights/where-does-china-stand-in-global-academic-publishing.

Lu Jinxiu (2004) Scientific Publication in China: An Overview and Some Thoughts on Improvement, Science Editor, July-August, Vol 27, No 4: 120-121.

Remler, D. (2018)Are 90\% of academic papers really never cited? Reviewing the literature on academic citations, http://blogs.lse.ac.uk/impactofsocialsciences/2014/04/23/ academic-papers-citation-rates-remler/.

Schema, H. (2014) The Birth of Modern Peer Review, https://blogs.scientificamerican .com/information-culture/the-birth-of-modern-peer-review/.

Spier, R. (2002). The history of the peer-review process. Trends in biotechnology, 20 (8), 357-8 PMID: 12127284.

Tausch, A. (2018) The Market Power of Global Scientific Publishing Companies in the Age of Globalization. An Analysis Based on the ocLC Worldcat, ssRN Electronic Journal, DOI: 10.2139/ssrn.3197632.

Zhang Yuehong, Wang Sen, Li Jiang (2002) The English-language academic journals of China: trends and developments, Learned Publishing Vol. 15 No. 2 April 2002:149-151.

Zhao, J., Gulbahar, B., Wang, L. (2017) Evaluating the Research Quality of Education Journals in China: Implications for Increasing Global Impact in Peripheral Countries, Review of Educational Research, https://doi.org/10.3102/0034654317690813. 